\title{
The Potential Use of Expert Systems to Enable Physicians to Order More Cost-Effective Diagnostic Imaging Examinations
}

\author{
Gillian D. Sanders and Edward A. Lyons
}

\begin{abstract}
Educating physicians to order diagnostic imaging examinations more cost-effectively is a difficult and time consuming task, which may be assisted significantly by the use of an expert system. This report is based on a study undertaken at the Health Sciences Centre in Winnipeg, Manitoba, to determine the feasibility of implementing an expert system to aid physicians in selecting appropriate imaging studies. The report reviews the potential benefits, requirements, and limitations of expert systems under development, and highlights the major issues to be considered in choosing such a system for implementation. An extensive literature search was done and is included to aid the reader interested in pursuing this opportunity for improving the cost-effective utilization of expensive diagnostic imaging resources.
\end{abstract}

Copyright 11991 by W.B. Saunders Company

KEY WORDS: expert systems, radiology, artificial intelligence, computer-assisted instruction, PHOENIX, information systems.

$\mathbf{R}^{A}$ ADIOLOGY IS A rapidly expanding field of medicine, making applicable and useful techniques obsolete in a few years time. The radiologist, as well as the physicians and clinicians who order the diagnostic imaging examinations, must stay up to date on these new advances and techniques. Choosing an inappropriate exam or the wrong sequence subjects the patient to unnecessary expense, radiation, or other forms of physical, emotional, or financial harm. To use examinations efficiently, the physician or clinician must use the patient's signs and symptoms to determine the most effective exam for clarifying the underlying disease.

Radiology technology today, although extremely beneficial, is also very costly. The most economic way to finance new technology and research is by eliminating unnecessary radiographic examinations and, therefore, expenses.

From the Department of Radiology, Health Sciences Center, Winnipeg, Manitoba, Canada.

Supported in part by Winthrop Diagnostic Imaging, Division of Sterling Drug Ltd, Aurora, Ontario L4G 3H6, Canada.

Address reprint requests to Dr Edward A. Lyons, Radiology Department, Health Sciences Center, 700 William Ave, Winnipeg, Manitoba, R3E OZ3, Canada.

Copyright $\odot 1991$ by W.B. Saunders Company

0897-1889/91/0402-0007\$03.00/0
The implementation of a radiology expert system could aid the department in several ways. The system could allow the radiology department to keep up to date on the exploding field of radiology, reduce unnecessary tests, and allow it to use its available resources to their full capacity, while moving towards the improvement of the overall quality of patient care.

\section{CURRENT ORDERING PROCEDURES}

Usually, the physician concentrates on providing the highest quality of patient care possible with little or no respect for the costs involved. ${ }^{1}$ The relationship between cost containment and quality of care, however, is a relationship that requires additional attention in all areas of medical care. Today, cost is a central issue in health care. The pursuit of quality care is frequently misguided. Many methods exist to regulate and discipline the medical profession to provide cost effective care. ${ }^{2}$ Despite such efforts, there are still many problems in the radiology department regarding the ordering and scheduling of radiologic examinations.

There are several reasons for the overuse and misuse of radiologic exams. Apprehension about malpractice, physician's lack of knowledge about testing, desire for definite certainty of diagnosis and patient demand are but a few of many factors that influence the physician's actions and usually lead to increased and unnecessary testing. ${ }^{3}$ It is important to encourage efficient and intelligent use of the available technology.

An increase in diagnostic imaging examinations over time is welcome when it can provide valuable clinical information. However, there is concern that physicians may be ordering an extreme number of tests. This problem is further amplified in teaching hospitals where medical students and young physicians first learn styles of patient care, resource use, and decisionmaking methods. ${ }^{3}$ In teaching hospitals, diagnostic tests are ordered significantly more often than in community hospitals, resulting in higher patient care costs. ${ }^{4}$ Most of these tests are attributed to educational purposes.

The use of radiology service was studied at 
the Health Sciences Center. ${ }^{5}$ It was determined in the study that "virtually all expenditures can be moderated if only high yield and important examinations are performed." Along with needless repeat studies, many examinations were either too early to follow an established illness, or ill-directed clinically. The authors believed that the utilization of radiologic exams was $30 \%$ greater than necessary. Of this $30 \%, 10 \%$ were duplicate or ill-directed; $10 \%$ would not have been necessary if previous medical information and tests could have been promptly available for the physician and the radiologists to use in their decision-making process and $10 \%$ were not justified because of either low yield, ill timing, or the little benefit they provided to the patient or society. ${ }^{5}$

The clinicians who request the examinations are usually the least knowledgeable about newer diagnostic imaging procedures, further aggravating the department's problems. The magnitude of expensive technologies that are available for the same clinical problems, with coinciding and sometimes conflicting benefits as well as costs, dangers, and other contradictions, make it difficult for the physician to decide among them. ${ }^{6}$ This reinforces the reasons for implementing an expert system into the department first as an educational device.

Radiologists currently have insufficient influence over the choice of tests. The separation of the various imaging departments from each other and the rest of the hospital has made it difficult for the radiologist to play an active role in diagnostic management. ${ }^{7}$ The likelihood, however, of having radiologists acting exclusively as advisors is not a realistic answer. In recent years, several methods have been used, attempting to limit the number of unnecessary tests. AR Martin et $\mathrm{al}^{3}$ discuss many of these methods. Such methods include monetary incentives, chart reviews, limits on the numbers of tests ordered in a day, notification of the physician about the use of tests in comparison with that of their peers, notification of a physician when a test did not meet their predetermined criteria for ordering, daily feedback of the tests costs to the physician, and frequent physician evaluation. None have proved effective or easy to evaluate.

Ideally a department would be able to use all of these methods with the assistance of com- puter technology that is cost-effective, user friendly, and capable of becoming an integral part of the department, even after the reduction of the problem of ill-ordered tests. However, it must be certain that economic concerns do not jeopardize the quality of patient care. ${ }^{6}$ Therefore, many hospitals are considering the acquisition of expert systems to help the radiologist in the advisory and critiquing role. The system would not only critique the proposed plan but play the role of a helpful tutor. An expert system, such as the PHOENIX system, would teach the user means of quantitative decision analysis, allowing him or her to become more aware of the rationale of ordering diagnostic imaging studies. The physician would be encouraged to identify the problem, the information needed to answer a question, and the best test that would provide that information.

Installing an expert system, interfaced with a Radiology Information Management System (RIMS), would reduce the department's resource problem. The computer aids the user in requesting examinations, critiques the user's diagnostic imaging plan, suggesting appropriate exams and indicating which tests are duplicate or redundant. Duplicate tests done at other hospitals, outside clinics, or even simply other departments, could be controlled. The expert system would be able to advise what the test would accomplish, showing if the dangers of the examination are greater than the value of the information given by the procedure. By limiting unnecessary tests, the radiology department could accommodate more needed examinations and reduce the waiting period for available exams.

Before implementing an expert system, evaluation of the ordering of imaging procedures would be done to measure the impact of the system on the radiology department. This evaluation would include determining the number of particular tests performed each year and comparing it to the yearly totals once the system had been installed. An effort would be made to decide whether a reduction in the amount of unwarranted radiologic examinations has been achieved. This, however, is extremely difficult since it requires deciding which tests were useful. One method is to have the referring doctor decide initially what benefit he antici- 
pates from a study and then, once performed, the actual benefit is realized as well as its effects on the patient's management. This decision is especially demanding in a teaching hospital since a test may be performed purely for its educational benefits. Although such a test may not aid the patient significantly, perhaps it will help the student, enabling him or her to be a more effective diagnostician in future years. Monitoring other variables such as waiting periods and average cost for the imaging patient or per disease process would serve as methods of evaluation.

\section{EXPERT SYSTEMS}

An "expert" or "knowledge-based" system is a computer program designed to represent and utilize factual knowledge of specific areas to solve problems. The systems use symbolic logic and heuristics (a rule of thumb or simplification that limits the search for solutions in domains that are difficult and poorly understood) to find solutions. Like human experts, they make mistakes and can learn from their errors. ${ }^{8}$ A computer-based expert system, however, has several advantages over human experts. The computer has increased reliability, consistency, and accessibility. It can find the desired information faster, and requires a shorter time to try alternatives. A particular advantage of the expert system is the ease with which its knowledge can be duplicated and therefore made available to a large number of individuals.

Expert systems have been developed for a multitude of application areas--such as geology, chemistry, military science and law-yet the medical domain is the most popular. One of the earliest and most widely known expert systems is MYCIN, developed at Stanford University. MYCIN helps a physician diagnose and treat infectious blood diseases and is now used for research and teaching. Other expert medical systems provide interpretation of medical test data, diagnosis, and recommended therapy. ${ }^{8}$

The PHOENIX expert system was developed at the University of Chicago for selecting the most appropriate diagnostic imaging procedures. The PHOENIX is a rule-based system, meaning that it expresses its knowledge about radiologic procedures by a set of rules. These rules are written as IF conditions followed by
THEN predicates. The advantages of a rulebased system, over other programming methods are its abilities to apply the rules to actual patient data, and to provide a method for justification of the rules. PHOENIX uses a forward chaining inference engine to set up the applicable rules. ${ }^{9}$ This means that the part of the expert system that contains the general problem-solving knowledge (the inference engine) uses a technique matching the IF portion of rules against facts to establish new facts which help to access and apply the domain knowledge. An expert system that is quite similar to the PHOENIX is the CASPER system developed by Greenes et al at the Harvard Medical school. CASPER (Computer-Aided Selection of Procedures and Evaluation of Results) is described in detail by Greenes. ${ }^{10}$ CASPER attempts to decide the suitable diagnostic workup strategy for clinical problems that involve diagnostic imaging procedures. ${ }^{10}$

Unlike expert systems such as CASNET ${ }^{11}$ and INTERNIST-I ${ }^{12}$ in the fields of glaucoma and general internal medicine respectively, PHOENIX uses a "critiquing" approach. This technique bases itself on the model originally developed by Perry Miller in the ATTENDING expert system, which critiques medical students' plans for anaesthetic management. ${ }^{13}$ Critiquing enhances a program's acceptability. In pure consultation systems, it may prove annoying for the user to have to override the computer's decisions and provide explanations. With the critiquing approach, the computer only interrupts when significant disagreement occurs. The system structures its responses to the physician's plans rather than trying to tell the physician what to do. It questions the physician, suggests alternatives, and explains its reasoning. ${ }^{9}$ This allows the user to take advantage of the ability of the computer to retain an immense amount of facts while still using human commonsense knowledge and intuition. The physician is never forced to act on the computer system's advice. The critiquing approach is particularly wellsuited for domains such as medicine, where decisions depend significantly on subjective judgement. ${ }^{14}$

An expert system should be viewed as a "tool." The greatest accountability still remains with the physician. This allows physicians to 
prepare plans on their own but to have those plans double-checked by the system before acting on them. ${ }^{13}$

\section{POTENTIAL USES AND BENEFITS}

Ideally, the expert system would fit into the normal routine of the radiology department, prove to be a successful educational tool, and help select the best imaging procedures to reduce the patient's hospital stay and hospital expenses. To accomplish these three tasks, there are several requirements the system needs to meet.

The expert system would have to produce clear responses to questions regarding complex clinical situations. Straightforward situations do not require computer aid (except in an educational setting). ${ }^{14}$ The system would have to be able to deal with difficulties such as spanning multiple problem areas, to have knowledge of interacting medical problems, to be able to suggest multiple procedures, to deal with contradictory or inconsistent data, and to be capable of dealing with complex, real situations while recognizing its own limits. Its knowledge base must be extensive enough to include all the procedures provided by the hospital, and to adapt its rules depending on which imaging tests are available in the specific hospital.

If an expert system is in a teaching hospital, it should be used not only for order entry and consultation but also for education. The system's function as a radiology consultant would be its first and most important task. To be a successful learning instrument it must be extremely user friendly. To accomplish this, the system would ideally come with various accessories such as an extensive manual, a quick reference pamphlet, tutorial program, practice module available for training purposes, training courses, and system specialist support accessible 24 hours per day, 7 days per week.

The expert system would work as the physician's ally rather than competitor. To do so, the system must maintain a record of its reasoning. It would provide constructive feedback on the user's performance, provide both explanations and references for its information and recommendations, and let the user review areas where he differed from the system's suggestions. The system would provide descriptions and explana- tions of the imaging procedures. The expert system would require the user to take account of previously ordered studies before requesting additional procedures, question the referring physician for relevant clinical information, and suggest alternative imaging procedures where appropriate.

Finally, to make the system a successful educational tool it would need to be user friendly. The user would be an active participant in the learning process rather than a passive recipient of information. The user can learn at a time that is convenient to him or her (this quality would be particularly helpful for a practising physician). Operating with a variety of different modes of input depending on the preference of the user (keyboard, touchscreen, mouse, light pen, voice) is a necessity. There must be a permanently available help function and menu. The system should request initial input from the user, not just tell him or her what to do. This required input could help the computer identify which users need further education and training in requesting radiology exams. The computer could provide motivation for the physicians to improve their performance, while documenting their success. ${ }^{15}$

Presently, there is a shift in the emphasis of medical students' training from memorization to the effective use of resources for information retrieval and problem solving. ${ }^{10}$ The use of an expert system in the radiology department is a method of using such information retrieval to its optimal potential. The system could encourage medical students' learning by prompting their curiosity and requiring them to consider other possibilities simply by having menus describing possible choices available. A question asked by the computer may alert the user to some crucial information that had not been taken into consideration in his initial diagnostic imaging plan. Although expert systems can be used as consultation devices, their implementation in teaching hospitals would require them to be not only critics but also effective teachers.

Expert systems should have additional applications and capabilities that would increase their value to the radiology department. They should have a brief response time and be accessible from patient wards on the hospitalwide information system. No time-sharing con- 
flicts should exist, and all information would be available online to be retrieved instantaneously. Linking the expert system with the hospital's existing Hospital Information System (HIS) would enable the expert system to consider specific patient demographics when suggesting appropriate radiologic examinations. The system should use a straightforward rule syntax so that prior computing programming experience would not be required to change rules that describe the decision-making process. This would allow easy updating and modification. Nonprogrammers would be able to extend the knowledge base. Ideally, the implementation of an expert system would encourage greater communication between referring physicians and radiologists in planning the imaging workup. Once the diagnostic strategy was determined, appropriate procedures could be ordered and scheduled.

Another benefit of an expert system would come with its eventual implementation into smaller hospitals and clinics. The physician would be able to make sure that the test he is ordering is the appropriate one, and avoid having his patient travel a distance to a larger hospitals only to discover that the examination is inconclusive, requiring further ordering of tests and travel for the patient. Hospitals with their own diagnostic imaging equipment could use the expert system not only as a critic but also as a method to ensure consideration of more up-to-date imaging techniques. The system would suggest the more appropriate test and provide references and explanations for the physician.

Even when the developed expert system is able to accomplish all the above tasks, its advice could still be rejected by the end-user. It must not infringe on the physician's management role. Shortliffe ${ }^{16}$ discusses many possible fears of physicians. Physicians may fear that the implementation of an expert system may cause them to lose their rapport with the patient. There is also the fear of loss of control, and of the challenge of independent problem solving. Conventionally, there is a tendency to be wary of any radical change. Therefore, implementation must involve as few changes to present clinical practices as possible. The system must be available when and where physicians usually make deci- sions (ie, office, hospital, home). The system must be easy for authorized users to access. If a system requires that a physician interrupt the normal pattern of patient care, it will likely fail. The system must be viewed as a helpful instrument, rather than a hindrance to efficiency or as a professional threat. ${ }^{16}$

Properly implemented, a model expert system would reduce problems related to the requesting of examinations in the radiology department without ever removing the actual decision-making from the physician.

\section{RIMS AND PACS}

There has been a rapidly growing interest in expert systems, not only as independent systems but as logical extensions of existing information systems. ${ }^{17}$ An important aspect of the expert system is its ability to interact with the RIMS.

The installation of a RIMS would eliminate several problems even without the added benefits of integration with an expert system. A RIMS would help the radiology department become more efficient. The RIMS provides various features including such as patient scheduling; patient registration; patient processing; patient tracking; film management; diagnostic reporting (transcription and management); inventory control; statistical reporting; billing; special interest and teaching files; and interface to the HIS

Joining the RIMS with the radiology expert system and eventually a Picture Archiving and Communication System (PACS) would allow the systems to consider all pertinent patient data, further increasing the physicians diagnostic capabilities.

A PACS is a computer system of storage, transmission, and display based on digital imaging. It is a system of stations interconnected by a network. The stations carry out key functions in medical imaging: acquisition stations (where the images are created by a diagnostic device in contact with a patient), display stations (where the images are selected and displayed), work stations (where images can be selected, displayed, manipulated, and annotated), and archives (where images can be stored for later recall and use) ${ }^{18}$ The advantages of digital films include less space taken up in archives; easy manipulation for image enhancement; availabil- 
ity to multiple users in different locations (hospital, office etc); and they are less subject to loss and pilferage. ${ }^{19}$

Radiologists would study the images on computer terminals and the transcribed report would then become part of the image record. Referring physicians could view the images and read the reports even in their offices. A radiologist and the referring physician could review findings by telephone while both concurrently studied the image on separate terminals. ${ }^{19}$

At present, existing PACS are limited in scope and use. The chief obstacles to the installation of PACS are equipment costs and the costs of the development of technology. ${ }^{20}$ The development of a complete system requires technical developments in several areas, including both hardware and software. Once such obstacles are overcome, PACS system will change the operation of imaging facilities and their relation to the rest of the health care system.

The combined system of a RIMS, HIS, expert system, and a PACS would lead to a total digital radiology department and move the department closer to its ultimate goal-the improvement of health care.

\section{CURRENT LIMITATIONS AND PROBLEMS}

At present, there are various limitations that restrict the implementation of expert systems in radiology departments. Several systems need extensive work on their knowledge bases in order to include all the procedures required.

The programmers of the expert system would need to be sure that all of the pertinent radiology procedures were covered by the system. At first those tests of greatest use and priority would be encoded into the system, followed by those tests of lesser importance and function. Tests could be ranked according to the frequency of their use and the magnitude of information they provide the radiologist.

Sources for the system's rules should be acquired from books, articles, and domain experts. It would be necessary to hire a support person to determine whether this information was up to date, and to modify this material when required. This support system employee would need the assistance of expert radiologists and physicians to review the system and help update its knowledge base. Such a review panel would ideally be found within the hospital itself. This would allow the system to remain up to date without demanding the additional cost of out-ofhouse experts.

A lot of research needs to be done on the user interfaces; the systems have to be made extremely easy and desirable to use. This would be the most difficult and time consuming aspect of a system's development. Another important aspect of the radiology expert system's future growth will be making it capable of being linked with an assortment of RIMS. Unfortunately, there is not one particular RIMS that dominates the information systems field. Therefore, the system would have to be able to mesh quite easily with various RIMS. Drawbacks regarding such aspects as response time and various other problems with interfaces and integration are technological limitations. These problems would decrease greatly with time and the expansion of computer technology. Elimination of such restrictions appears to be possible with extensive research, development, and time. With these components, the model expert system would be moving towards becoming an ideal system for widespread installation into hospitals.

\section{SYSTEM EVALUATION AND TESTING}

Before implementing any system into a radiology department, the expectations of the system and how it will be evaluated must be determined. An extensive discussion of the need for such a continual study of the system's abilities is found in Shortliffe and Buchanan. ${ }^{23}$ The long range goals, motives, and expectations for building and implementing an expert system must be identified. It is important to remember that although the system could help reduce the use of radiologic examinations, its primary goal would be to help its users become more efficient and knowledgeable regarding the ordering of radiologic tests. The expert system would initially be used for education and would be expected to serve as a teacher to clinicians, physicians, or others who needed or wanted to use the system. Primary evaluation would be done by these users. Their initial reactions to the system as well as their continued use and any visible changes in their decisions regarding radiologic examinations would act as the hospi- 
tal's primary indicator regarding the system's success. After an order-entry expert system was implemented, a more extensive evaluation would be done. It would be possible to evaluate if any radiologic workup changes occurred because of the system's critiques. Changes in the use of tests and any increase in the overall efficiency of the radiology department could also be surveyed. By measuring pertinent parameters such as patient waiting time for available tests, overall use of tests, and the frequency of irrelevant or duplicate tests (before and after system use), the department could more accurately rate the system's performance.

An significant area where the expert system should be tested is its ability to improve patient care (through fewer management errors and appropriate examinations). Also of importance is whether the system is used. A computer system may be able to do many wonderful feats and solve great numbers of problems but if the physician does not use the system (either because of distrust of computers, the system's inability to integrate into the everyday practice of the physician, or for numerous other reasons), then the system is a waste. One way to avoid this is to be aware of what the user would be comfortable using, how best to integrate it into the department, and what features would make it more attractive and helpful to its users.

The expert system would be tested on how close it is to the department's "ideal" system, whether its reasoning is "correct," its input/ output content and medium, its efficiency and cost effectiveness, the response time, necessary time commitment of the user, success when dealing with test cases, and the ease of maintaining its knowledge base current and accurate.

Before being used for clinical use, the system's knowledge would be tested for accuracy, completeness, and consistency. It would be important to determine a standard by which to measure the system's performance. Once the system is in actual clinical use, the evaluators would concentrate on the physician's actions (whether the user alters his or her behavior based on the system's advice).

The expert system program would be rated on its ability to give "correct" answers. We must define whether the radiology department ex- pects "correct" answers, as in the Truth, or simply the same as a human expert. Some radiologists are not as concerned with the system's ability to provide the Truth but rather its skill in giving explanations and justification for its recommendations. ${ }^{11}$ Such explanations help develop the user's trust in the computer, as well as serve as a method for detecting errors in the logic of the knowledge base.

The initial function of the expert system as a tutor would allow the user to become comfortable and confident with the system while drilling the system's intelligence and thus uncovering any areas of weakness. ${ }^{24}$

Many of the system's shortcomings are caused by limitations of current technology. We must separate the evaluation of the system's design from such technological weaknesses. It must then be determined if there is any way to lessen the effect of these limitations on the system's capabilities, or to help technology to advance, enabling these restrictions to be eliminated.

\section{FUTURE OPPORTUNITIES}

Once an expert system is established in the department, researchers could begin concentrating on the feasibility of integrating a PACS system. The combined package of the RIMS, expert system, and eventually the PACS would greatly benefit the radiology department. The advancement of the techniques and examinations with which the physicians and clinicians (as well as the radiologists) are familiar and comfortable would increase.

Ideally, with minimal programming changes, the expert system would be installed in hospitals across North America. This would allow greater communication between radiology departments and provide both the hospital and the patient with additional benefits.

Unfortunately, there is not one exclusive RIMS that dominates the market. This signifies that the developed system will have to be reasonably generic so that it could be linked with a variety of systems. Fortunately, the majority of working RIMS are written in Massachusetts General Hospital Utility Multi-Programming Unit (MUMPS). Once the system is developed and installed in one hospital, supple- 
mentary work would be done so that the system could be situated in separate hospitals with different RIMS.

\section{CONCLUSION}

Of all the medical disciplines, diagnostic radiology is most dependent on computer technology. Numerous of the imaging techniques introduced during the last 20 years would not exist were it not for the advanced hardware and software that propels them. However, educational uses of computers in radiology have been significantly lacking. ${ }^{25}$ An expert system radiology consultant would be a step towards ending this void.

A certain degree of uncertainty and therefore misuse of diagnostic imaging examinations will always be present in the medical practice and will not be eliminated by any technique, however powerful. An expert order entry system would attempt to help the physician come to the best decision given the restrictions imposed by these uncertainties.

An ideal expert system would aid the hospital in which it was implemented in numerous ways. It would help eliminate needless examinations. At the same time, it would be aiding physicians, clinicians, and radiologists to keep up-to-date and familiar with the latest diagnostic imaging techniques and their applications. Those who develop and install radiology expert systems in the future will be provided with a rewarding and educational experience. The most significant benefit, however, will be for the forthcoming patient who receives an improved level of health care.

\section{REFERENCES}

1. Carels EJ, Tabatabai C: Increased utilization of laboratory tests and $\mathrm{x}$-rays: Effect on quality and cost of health care. QRB June:5-10, 1980

2. Cunningham RD, Friedman $\mathrm{CP}$, Weaver $\mathrm{B}$ (eds): Medical Education: Making the Grade in Cost Containment. Battle Creek, MI, Kellogg Foundation, 1986

3. Martin AR, Wolf MA, Thibodeau LA, et al: A trial of two strategies to modify the test-ordering behaviour of medical residents. N Engl J Med 303:1330-1336, 1980

4. Garg ML, Gliebe WA, Elkhatib MB: Diagnostic testing as a cost factor in teaching hospitals. Hospitals JAHA 52:97-100, 1978

5. MacEwan DW, Kiernan MK: Methods of radiology cost restraint in a teaching hospital. J Can Assoc Radiol 24:188-91, 1973

6. Greenes RA: Toward more effective radiologic consultation: Design of a desktop workstation to aid in the selection and interpretation of diagnostic procedures. Proceedings of the Eighth Conference on Computer Applications in Radiology, St Louis, MO, May 23, 1984

7. Baker S: Conduit or gatekeeper. Administrative Radiol 4:12-14, 1988

8. Waterman DA: A Guide to Expert Systems. Reading, MA, Addison-Wesley, 1986

9. Kahn CE Jr, Kovatsis PG, Messersmith RN, et al: Automated entry of radiology requisition information with artificial-intelligence techniques. Am J Roentgenol 153: $1085-8,1989$

10. Greenes RA, Tarbar DB, Krauss M, et al: Knowledge management as a decision support method: A diagnostic workup strategy application. Comput Biomed Res 22:113135,1989

11. Kulikowski CA, Weiss SM: Representation of expert knowledge for consultation: The CASNET and EXPERT projects, in Szolovits $P$ (ed): Artificial Intelligence in Medicine. Boulder, CO, Westview, 1982
12. Miller RA, Pople HE Jr, Myers JD: INTERNIST-I, An experimental computer-based diagnostic consultant for general internal medicine. N Engl J Med 307:468-476, 1982

13. Miller PL: Critiquing anaesthetic management: The ATTENDING computer system. Anaesthesiology 58:362369,1983

14. Miller PL, Blumenfrucht SJ, Rose JR, et al: HYDRA: A knowledge acquisition tool for expert systems that critique medical workup. Med Decis Making 7:12-21, 1987

15. Shortliffe EH: Computer programs to support clinical decision making. JAMA 258:61-66, 1987

16. Anbar M: Computer assisted clinical decisions: Present scope, limitations, and future. Int J Tech Assessment in Health Care 2:168-176, 1986

17. Jost RG, Rodewald SS, Hill RL, et al: A computer system to monitor radiology department açtivity: A management tool to improve patient care. Radiology 145:347-350, 1982

18. Shortliffe EH. Testing reality: The introduction of decision-support technologies for physicians. Meth Inform Med 28:1-5, 1989

19. Kwa HY, van der Lei J, Kors JA: Expert systems integrated with information systems. Comput Programs Biomed 25:327-332, 1987

20. Steering Committee on Future Health Scenarios: Anticipating and Assessing Health Care Technology (vol 7). Computer Assisted Medical Imaging: The Case of Picture Archiving and Communications Systems (PACS). Boston, MA, Kluwer, 1988

21. Drew PG: Picture Archiving and Communication Systems. Hospitals JAHA 59:78-86, 1985

22. Brink JV: What radiologists say about PACS. AJR 146:419-420, 1986

23. Shortiiffe EH, Buchanan BG: The problem of evaluation in rule based expert systems, in Shortliffe EH, Buchanan BG (eds): Based Expert Systems: The MYCIN 
Experiments of the Stanford Heuristic Programming Project. Reading, MA, Addison-Wesley, 1984

24. Miller PL: The Evaluation of Artificial intelligence systems in Medicine. Comput Programs Biomed 22:5-11, 1986

25. Tessler FN: Computer Applications in Radiology Education: A Challenge for the 1990s. AJR 152:1169-1172, 1989

\section{APPENDIX}

\section{Additional References Not Specifically Cited Within the Article}

Armstrong P, Black WC: Optimum utilisation of radiological tests: The radiologist as advisor. Clin Radiol 40:444-7, 1989

Aronberg DJ, Rodewald SS, Jost RG: Computer-assisted instruction in radiology. Radiology 154:345-347, 1985

Athanasoulis CA, Lee AK: Algorithms in radiology and medical imaging. Radiology 164:565-567, 1987

Bankowitz RA, McNeil MA, Challinor SM, et al: A computer-assisted medical diagnostic consultation service: Implementation and prospective evaluation of a prototype. Ann Internal Med 110:824-832, 1989

Bankowitz RA, McNeil MA, Challinor SM, et al: Effect of a computer-assisted general medicine diagnostic consultation service on housestaff diagnostic strategy, in Salamon R, Protti D, Moehr J (eds): International Symposium of Medical Informatics and Education. University of Victoria, BC, Canada, May 1989

Barnett GO, Cimino JJ, Hupp JA, et al: DXplain: An evolving diagnostic decision-support system. JAMA 258: 67-74, 1987

Barnhard HJ, Lane GB: The computerized diagnostic radiology department: Update 1982. Radiology 145:551558,1982

Barstow DR: Knowledge-Based Program Construction. New York, NY, North Holland, 1979

Basden A: On application of expert systems, in Coombs MJ (ed): Developments in Expert Systems London, Academic, 1984

Bell HS, Enzmann DR: A computerized economic model for a radiology department considering PACS. Proceedings of the Eighth Conference on Computer Applications In Radiology. St Louis, MO, May 23, 1984

Bleich HL: Computer-based consultation: Electrolyte and acid-based disorders. Am J Med 53:285-291, 1972

Bradigan PS, Mularski CA: End-user searching in a medical school curriculum: An evaluated modular approach. Bull Med Libr Assoc Oct 77:348-356, 1989

Brigham CR: Programming languages used for health sciences computer-assisted instruction. Massachusetts General Hospital, Lister Hill National Center for Biomedical Communications, August 1973

Broering NC, Corn M, Ayers WR, et al: Implementing RECONSIDER, a diagnostic prompting computer system, at the Georgetown university medical center. Bull Med Libr Assoc April 76:155-158, 1988

Choplin RH, Boehme JM, Park WC, et al: Fiscal impact of a radiology information management system. Proceedings of the Eighth Conference on Computer Applications in Radiology. St Louis, MO, May 23, 1984

Clifton DS Jr: Fyffe DE Project Feasibility Analysis: A Guide To Profitable New Ventures. New York, NY, Wiley, 1977

Counte MA, Kjerulff KH, Salloway JC, et al: Adapting to the implementation of a medical information system: A comparison of short- versus long-term findings. J Med Syst 11:11-20, 1987

Covvey HD, Craven NH, McAlister NH: Concepts and Issues in Health Care Computing. St Louis, MO, Mosby, 1985

Davidson RC, Diaz MA, Horton JL, et al: The use of MUMPS in a departmental computerized clinical data system. J Fam Pract 19:697-700, 1984

Davis RG: MUMPS Technology: Heading into the mainstream, in Computers in Healthcare: MUMPS Special Edition. Duluth, MN, Cardiff, 1990

Doyle T, Hare W, Thomson K, et al: Procedures in Diagnostic Radiology. Edinburgh, Churchill Livingstone, 1989

Eisenberg JM, Williams SV, Garner L, et al: Computerbased audit to detect and correct overutilization of laboratory tests. Medical Care 15:915-921, 1977

Feuer AR, Gehani N (eds): Comparing and Assessing Programming Languages: Ada, C, and Pascal. Englewood Cliffs, NJ, Prentice-Hall, 1984

Forman HP, Leonidas JC, Kirks DR: Clinical activities of pediatric radiologists in the United States and Canada: 10-year follow-up. Radiology Apr 175:127-9, 1990

Gatsonis C, McNeil BJ: Collaborative evaluations of diagnostic tests: Experience of the radiology diagnostic oncology group. Radiology May 175:571-5, 1990

Gray JE, Karsell PR, Becker GP, et al: Total digital radiology: Is it feasible? or desirable? AJR 143:13451349, 1984

Greenes RA, Shortliffe EH: Medical informatics: An emerging academic discipline and institutional priority. JAMA 263:1114-1120, 1990

Greenes RA: Desktop Knowledge: A new focus for medical education and decision support, in Salamon R, Protti D, Moehr J (eds): International Symposium of Medical Informatics and Education. University of Victoria, BC, Canada May, 1989

Greenes RA: Computer-aided diagnostic strategy selection. Radiol Clin North Am 24:105-120, 1986

Greenes RA: MUMPS: Second Decade Design Considerations. Comput Biomed Res 14:104-11, 1981

Greenes RA, Pappalardo AN, Marble CW, et al: Design and implementation of a clinical data management system. Comput Biomed Res 2:469-485, 1969

Griner PF, Glaser RJ: Misuse of laboratory tests and diagnostic procedures. N Engl J Med 307:1336-1339, 1982

Grossman RM: A review of physician cost-containment strategies for laboratory testing. Med Care 21:783-802, 1983

Hahn DR, Van Farowe DE: Misuse and abuse of diagnostic x-ray. Am J Public Health Nations Health 60:250-4, 1970

Hansen GC, Falkenbach KH, Yaghmai I: Voice Recognition System. Radiology 169:580, 1988

Hardwick DF, Morrison JI, Cassidy PA: Managing lab costs 
and utilization: Balance supply and demand. Dimensions 62:18-22, 1985

Henschke CI, Balter S, Whalen JP, et al: Diagnostic protocols for radiologic efficiency. Administrative Radiol Nov:26-28, 1988

Health Sciences Center: Department of Radiology: Computer System Software Requirements Specification. Winnipeg, Manitoba, 1986

Husack GA, Gibbons RW: A Do-It-Yourself Feasibility Study: New Retail Ventures. Canada: The Institute for Small Business Inc, 1979

Jacobs P, Hart W: Admission waiting times: A national survey. Dimens Health Serv 67:32-4, 1990

Jacobson HG: Machines and people: who and what are important? (editorial) JAMA 252:1181-2, 1984

Jacoby CG, Smith WL, Albanese MA: An evaluation of computer-assisted instruction in radiology. AJR 143:675677,1984

Jansen BH, Dawant BM: Knowledge-based approach to sleep EEG analysis-A feasibility study. IEEE Trans Biomed Eng 36:510-518, 1989

Javitt J: Computers in Medicine: Applications and Possibilities. Philadelphia, PA, Saunders, 1986

Kahn CE Jr, Messersmith RN, Jokich MD: PHOENIX. An expert system for selecting diagnostic imaging procedures. Invest Radiol 22:978-80, 1987

Kruger RA: When tomorrow comes: Computerized decision making. Invest Radiol 23:239, 1988

Kulikowski CA, Weiss SM: Representation of expert knowledge for consultation: The CASNET and EXPERT projects, in Szolovits $P$ (ed): Artificial Intelligence in Medicine. Boulder, CO, Westview, 1982

Langlotz CP, Shortliffe EH: Adapting a consultation system to critique user plans, in Coombs MJ (ed): Developments in Expert Systems. London, Academic, 1984

Lau J, Kassirer JP, Pauker SG: DECISION MAKER 3.0: Improved decision analysis by personal computer. Med Decis Making 3:39-43, 1983

Lehr JL: Software: Basics and Applications in Radiology. Sem Ultrasound 4:260-269, 1983

Lehr JL, Steinberg FL: The radiology information system: Its evolution and current status. Crit Rev Med Inform 3:259-309, 1987

Lehr JL: Installation of MARS at the University of Chicago. Proceedings of the Eighth Conference on Computer Applications in Radiology, St Louis, MO, May 23, 1984

Lehr JL, Lodwick GS, Nicholson BF, et al: Experience with MARS (Missouri automated radiology system). Radiology 106:289-294, 1973

Levin DC, Matteucci T: Do radiologists control imaging studies? Survey results from 198 academic institutions. Radiology 170:879-81, 1989

MacEwan DW: Radiology services on a tight budget. J Can Assoc Radiol 31:129-134, 1980

MacEwan DW: Equilibrium of medical and radiology services in Manitoba. Radiology 156:289-294, 1985

MacIntosh OC: Use and Abuse of Diagnostic Services: The Canadian Experience. Montreal, Canada, Eden, 1982

MacLennan BJ: Principles of Programming Languages: Design, Evaluation, and Implementation. New York, NY, Holt, Rinehart and Winston, 1983
Marcus S, McDermott J, Wang T: Knowledge acquisition for constructive systems, in Proceedings of the Ninth International Joint Conference on Artificial Intelligence. Los Angeles, CA, 1985

Martin DL: Radiology under fire: Limiting x-ray use. Dimensions 61:32, 1984

McGettrick AD: The Definition of Programming Languages. Cambridge, Cambridge Univ Press, 1980

McNeil BJ, Abrams HL (ed): Brigham and Women's Hospital Handbook of Diagnostic Imaging. Boston MA, Little, Brown, 1986

McNeil BJ, Keeler E, Adelstein SJ: Primer on certain elements of medical decision making. $\mathbf{N}$ Engl $\mathrm{J}$ Med 293:211-215, 1975

Miller PL: Evaluation of artificial intelligence systems in medicine, in Miller PL (ed): Selected Topics in Medical Artificial intelligence. New York, NY, Springer-Verlag, 1988

Miller PL: Expert Critiquing Systems: Practice-Based Medical Consultation by Computer. New York, NY, SpringerVerlag, 1986

Miller PL, Shaw C, Rose JR, et al: Critiquing the process of radiologic of differential diagnosis. Comput Programs Biomed 22:21-25, 1986

Miller RA, Pople HE Jr, Myers JD: INTERNIST-I, An experimental computer-based diagnostic consultant for general internal medicine. N Engl J Med 307:468-476, 1982

Milne ENC: The conventional chest radiograph-does it have a future? Applied Radiol Mar/Apr:13-14, 1985

Mooney R, Dejong G: Learning schemata for natural language processing, in Proceedings of the Ninth International Joint Conference on Artificial Intelligence. Los Angeles, CA, 1985

Nelson SJ, Tuttle MS, Harrison P, et al: Evaluating RECONSIDER: A computer program for diagnostic prompting. J Med Syst 516:379-388, 1985

Neves DM: Learning procedures from examples and by doing, in Proceedings of the Ninth International Joint Conference on Artificial Intelligence. Los Angeles, CA, 1985

Nguyen TA, Perkins WA, Laffey TJ, et al: Checking an expert system knowledge base for consistency and completeness, in Proceedings of the Ninth International Joint Conference on Artificial Intelligence. Los Angeles, CA, 1985

O'Desky RI, Ball MJ, Ball EE: Computers in health care for the 21st century. Methods Inform Med 29:158-161, 1990

Pfaff GE (ed): User Interface Management Systems. Berlin, Springer-Verlag, 1983

Pollock E: Integrating with MUMPS: Fast, flexible and affordable, in Computers in Healthcare: MUMPS Special Edition. Duluth, MN, Cardiff, 1990

Rajamoney S, Dejong G, Faltings B: Towards a model of conceptual knowledge acquisition through directed experimentation, in Proceedings of the Ninth International Joint Conference on Artificial Intelligence, Los Angeles, CA, 1985

Renfrew DL, El-Khoury GY, Jacoby CG: Computerassisted instruction in radiology. Radiology 143:574, 1982

Robbins AH, Horowitz DM, Srinivasan MK, et al: Speech- 
controlled generation of radiology reports. Radiology 164:569-573, 1987

Rudy TE, Turk DC, Brena SF: Differential utility of medical procedures in the assessment of chronic pain patients. Pain Jul 34:53-60, 1988

Sanderson PC: Computer Languages: A Practical Guide to the Chief Programming Languages. London, NewnesButterworths, 1970

Schaeffer J: The utility of expert knowledge, in Proceedings of the Ninth International Joint Conference on Artificial Intelligence, Los Angeles, CA, 1985

Schreiner A, Chard T: Expert systems for the prediction of ovulation: Comparison of an expert system shell (Expertech Xi Plus) with a program written in a traditional language (BASIC). Meth Inform Med 29:140-145, 1990

Shortliffe EH: Medical expert systems-knowledge tools for physicians. West J Med 145:830-839, 1986

Shortliffe EH, Clancey WJ: Readings in Medical Artificial Intelligence: The First Decade. Reading, MA, AddisonWesley, 1984

Shortliffe EH, Teach RL: An analysis of physician attitudes regarding computer-based clinical consultation systems. Comput Biomed Res 14:542-558, 1981

Sox HC: Decision analysis: A basic clinical skill? New Engl J Med 316:271-272, 1987

Straub WH (ed): Manual of diagnostic Imaging: A Clinician's Guide to clinical Problem Solving (2nd ed). Boston, MA, Little, Brown, 1989

Swett HA, Fisher PR, Cohn AI, et al: Expert systemcontrolled image display. Radiology 172:487-493, 1989

Swett HA, Fisher PR, Mutalik P, et al: The IMAGE/ICON system: Voice activated intelligent image display for radiologic diagnosis, in Kingsland LC III (ed): The Thirteenth Annual Symposium on Computer Applica- tions in Medical Care. Washington, DC, IEEE Computer Society Press, 977-978, 1989

Swett HA, Rothschild M, Weltin GG, et al: Optimizing radiologic workup: An artificial intelligence approach. Radiology 165:131, 1987

Swett HA, Miller PL: ICON: A computer-based approach to differential diagnosis in radiology. Radiology 163:555558,1987

Tuhrim S, Reggia JA: Feasibility of physician-developed expert systems. Med Decis Making 6:23-26, 1986

Van Bemmel JH, Gremy F, Zvarova J (eds): Medical Decision Making: Diagnostic Strategies and Expert Systems. New York, NY, North Holland, 1985

Wang Y, Best DE, Hoffman JG, et al: ACR-NEMA digital imaging and communications standards: Minimum requirements. Radiology 166:529-532, 1988

Weiss SM, Kulikowski CA: A Practical Guide to Designing Expert Systems. NJ, Rowman \& Allanheld, 1984

West PA: Who is monitoring the use of diagnostic services? Hosp and Health Serv Rev March 80:79-80, 1984

World Health Organization: A rational approach to radiodiagnostic investigations. Technical report \#689. World Health Organization, Geneva, 1983

Williams RC, Boehme JM, Choplin RH, et al: Often overlooked considerations in implementing computer systems. Proceedings in the Eighth Conference on Computer Applications in Radiology. St Louis, MO, May 23, 1984

Zientara GP: The role of artificial intelligence in medical imaging. Invest Radiol 23:68-70, 1988

Zink S: The promise of a new technology: Knowledge-based systems in radiation oncology and diagnostic radiology. Comput Med Imag Grap 13:281-293, 1989 